\title{
EFEITOS DA ADIÇÃO DE AGENTES TRÓFICOS NA DIETA DE LEITÕES DESMAMADOS SOBRE A EXPRESSÃO DA ENZIMA ORNITINA DESCARBOXILASE, OS CONTEÚDOS DE PROTEÍNA E DNA E O DESEMPENHO
}

\author{
FERNANDA MARCUSSI TUCCI ${ }^{1}$, MARIA CRISTINA THOMAZ², MELISSA IZABEl HANNAS ${ }^{3}$, \\ ANTÔNIO JOÃO SCANDOLERA ${ }^{4}$, FÁBIO ENRIQUE LEMOS BUDIÑO ${ }^{5}$ \\ ${ }^{1}$ Zootecnista, Ministério da Agricultura, Pecuária e Abastecimento, Brasília DF, Brasil. \\ ${ }^{2}$ Professora Doutora da Faculdade de Ciências Agrárias e Veterinárias da UNESP, Jaboticabal, SP, \\ Brasil. \\ ${ }^{3}$ Professora Doutora da Universidade Federal de Viçosa, Viçosa, MG, Brasil. \\ ${ }^{4}$ Professor Doutor da Universidade Federal do Paraná, Curitiba, PR, Brasil. \\ ${ }^{5}$ Pesquisador Doutor do Instituto de Zootecnia, Agência Paulista de Tecnologia dos Agronegócios, \\ Nova Odessa, SP, Brasil - fbudino@iz.sp.gov.br
}

Foram conduzidos dois experimentos para avaliar o efeito
da adição de glutamina, óleo de peixe ou parede celular de
levedura à dieta de leitões desmamados sobre a expressão
da enzima ornitina descarboxilase (ODC), o conteúdo de
proteína e DNA em amostras de intestino delgado e o
desempenho. No primeiro experimento foram utilizados
24 leitões desmamados para medir o desempenho nas
fases pré-inicial, inicial 1 e inicial 2 . Foram testadas
quatro dietas (T1 - dieta basal (DB); T2 - DB + $1 \%$ de
glutamina; T3 - DB + 0,2\% de parede celular de levedura;
T4 - DB + 5\% de óleo de peixe). No segundo experimento
foram utilizados 45 leitões desmamados e distribuídos

\section{RESUMO}

num delineamento em blocos casualizados, em esquema fatorial, com quatro dietas e três idades de abate (ao desmame, sete e 14 dias pós-desmame). As dietas testadas não alteraram o desempenho dos leitões em nenhuma das fases. Houve redução da expressão da enzima ODC, da concentração de proteína e da relação proteína/DNA aos sete dias pós-desmame, com aumento dos valores aos 14 dias, evidenciando um estado de hipotrofia da mucosa, sugerindo que o processo de síntese protéica no intestino delgado ficou comprometido na primeira semana após o desmame, e apresentou sinais de recuperação na segunda semana.

PALAVRAS-CHAVE: ácidos graxos poliinsaturados; glutamina; prebiótico; suíno.

\section{EFFECTS OF THE ADDITION OF TROFIC AGENTS IN WEANED PIGLETS DIET ON THE EXPRESSION OF THE ENZYME ORNITHINE DECARBOXYLASE, ON THE CONTENTS OF PROTEIN AND DNA AND ON PERFORMANCE}

\section{ABSTRACT}

Two experiments were carried out to evaluate the effect of adding glutamine, fish oil or yeast cellular wall to the diet of weaned piglets on the expression of the enzyme ornithine decarboxylase (ODC), the protein content and DNA in small intestine samples and on performance. In the first experiment, 24 weaned piglets were used to measure the performance at the phases prestarter, starter 1 and starter 2. Four diets were tested (T1 - basal diet (BD); $\mathrm{T} 2-\mathrm{BD}+1 \%$ of glutamine; $\mathrm{T} 3-\mathrm{BD}+0,2 \%$ of yeast cellular wall; $\mathrm{T} 4-\mathrm{BD}+5 \%$ of fish oil). At the second 
experiment 45 weaned piglets were used and distributed in a randomized block design, in factorial outline with four diets and three slaughter ages (on the day of weaning, on the seventh and fourteenth days postweaning). The tested diets did not alter the piglets' performance in none of the phases. There was reduction of the expression of the ODC enzyme, of the protein concentration and of the relationship protein/DNA to the seven days postweaning, with increase of the values on the $14^{\text {th }}$ day, evidencing a state of hypotrophy of the mucous membrane, suggesting that the process of protein synthesis in the small intestine was diminished in the first week after weaning, but it presented recovery signs in the second week.

KEYWORDS: glutamine; polyunsaturated fatty acids; prebiotic; swine.

\section{INTRODUÇÃO}

O desenvolvimento da mucosa dos animais é dependente de fatores endógenos (sistemas endócrino e nervoso) e exógenos (tipo de dieta, qualidade e quantidade dos ingredientes). Os efeitos tróficos dos nutrientes podem estar relacionados com a descamação, nutrição local e estímulo do crescimento por nutrientes específicos, independente do seu valor nutritivo ${ }^{1}$.

Dentre os agentes com ação trófica na mucosa intestinal encontram-se as poliaminas (putrescina, espermina e espermidina), que são essenciais para o crescimento e proliferação celular ${ }^{2}$. Segundo Wang et al. ${ }^{3}$, os níveis intracelulares das poliaminas são altamente regulados e completamente dependentes da ativação ou inibição da ornitina descarboxilase (ODC), que catalisa a conversão da ornitina em putrescina (precursora da espermidina e espermina).

A ativação da ODC no intestino após alimentação é produzida tanto por estimulação direta do conteúdo luminal como por mecanismos humorais, sendo que a estimulação direta é a principal responsável ${ }^{4}$. Tabata e Johnson ${ }^{4}$ também apontaram para a necessidade da presença de aminas da dieta no conteúdo luminal. Segundo Wang et al. ${ }^{5}$, as aminas simples e os aminoácidos das dietas podem estimular a atividade da ODC na mucosa, uma vez que existem evidências de que a asparagina, glutamina, serina e glicina, quando presentes no conteúdo luminal, estimulam o crescimento da mucosa através da expressão do gene da ODC. Kandil et al. ${ }^{6}$ também constataram aumento da atividade da ODC e da proliferação celular no jejuno de leitões com a administração de glutamina, sugerindo que a administração terapêutica deste aminoácido pode facilitar a recuperação do epitélio em casos de diarreia crônica.

Lin et al. ${ }^{7}$ sugeriram que a ODC pode ser utilizada como um marcador precoce do crescimento intestinal durante o processo de desmame em ratos, uma vez que o aumento da ODC foi seguido de aumento da divisão celular, aumento dos conteúdos de DNA e proteína. Por outro lado, a relação entre proteína DNA nos tecidos pode dar uma indicação da hipertrofia dos mesmos ${ }^{8}$.

A suplementação com glutamina na dieta de leitões desmamados tem mostrado resultados satisfatórios. Wu et al. ${ }^{9}$ concluíram que a suplementação da dieta de leitões com $1 \%$ de glutamina preveniu a atrofia dos vilos na primeira semana pós-desmame e melhorou o desempenho em $25 \%$ na segunda semana pós-desmame.

$\mathrm{O}$ efeito benéfico do uso de glutamina na dieta sobre as características estruturais da mucosa intestinal também foi observado em frangos de corte que foram submetidos à restrição alimentar ${ }^{10}$. Observou-se também aumento na expressão da ornitina descarboxilase nas aves que foram suplementadas com glutamina ${ }^{10}$.

A administração de ácidos graxos poliinsaturados de cadeia longa para leitões que sofreram restrição alimentar por 30 dias melhorou a recuperação das lesões histopatológicas no intestino delgado e elevou os níveis de proteína, DNA, colesterol e fosfolipídeos na mucosa do jejuno ${ }^{11}$.

Os oligossacarídeos (prebióticos), presentes na parede celular de levedura podem afetar a mucosa intestinal alterando a microbiota, agindo de duas maneiras: através do fornecimento de nutrientes a bactérias desejáveis ou da eliminação de microorganismos patogênicos, resultando em menor incidência de infecções e maior integridade da mucosa intestinal ${ }^{12}$.

O objetivo deste trabalho foi o de avaliar o efeito da adição de agentes tróficos na dieta de leitões ao desmame sobre a expressão da enzima ornitina descarboxilase, os conteúdos de proteína e DNA e o desempenho.

\section{MATERIAL E MÉTODOS}

Foram conduzidos dois experimentos distintos na Câmara Bioclimática do Departamento de Morfologia e Fisiologia Animal e no Laboratório 
de Biologia Molecular do Departamento de Tecnologia da FCAV/UNESP - Câmpus de Jaboticabal, para avaliar os efeitos da inclusão de glutamina, ácidos graxos poliinsaturados (óleo de peixe) ou parede celular de levedura (S. cerevisiae) na dieta de leitões desmamados sobre o desempenho e taxa de renovação celular da mucosa intestinal. $\mathrm{O}$ presente estudo foi aprovado pelo Comitê de Ética em Uso de Animais sob o protocolo número 0178973/14.

O Experimento 1 foi realizado para avaliar o desempenho dos leitões nas fases pré-inicial (de 22 a 34 dias de idade), inicial 1 (de 35 a 47dias) e inicial 2 (de 48 a 61 dias). Foram utilizados 24 leitões de mesma linhagem, desmamados aos 22 dias de idade, com peso médio de $6,46 \pm 0,44 \mathrm{~kg}$. Os animais foram mantidos em temperatura de conforto térmico para evitar interferências do ambiente, sendo alojados em gaiolas metálicas suspensas, dotadas de bebedouros tipo chupeta e comedouros tipo cocho, recebendo ração e água à vontade e iguais condições de manejo.

Os tratamentos foram: 1-dieta basal; 2-dieta basal $+1 \%$ de glutamina; 3 -dieta basal $+0,2 \%$ de parede celular de levedura (prebiótico); 4-dieta basal $+5 \%$ de óleo de peixe (em substituição ao óleo de soja). A dieta basal dos tratamentos 1,2 e 3 foi formulada com óleo de soja, enquanto que a dieta basal 4 foi formulada com óleo de peixe. $\mathrm{O}$ óleo de peixe foi escolhido para constituir um dos tratamentos devido à alta concentração de ácidos graxos poliinsaturados ${ }^{13}$.

As dietas experimentais, formuladas de modo a atender as exigências nutricionais dos animais em cada fase ${ }^{14}$, estão apresentadas na Tabela 1. Foram avaliados ganho de peso, consumo de ração e conversão alimentar, a partir das medidas de peso corporal e consumo de ração, que foram determinados periodicamente $(22,34,47$ e 61 dias de idade).

Tabela 1 - Composição e níveis nutricionais das dietas basais por fase

\begin{tabular}{|c|c|c|c|}
\hline Ingrediente $(\%)$ & Pré-inicial & Inicial 1 & Inicial 2 \\
\hline Milho & 41,99 & 46,18 & 54,47 \\
\hline Farelo de soja & 19,00 & 23,35 & 32,70 \\
\hline Leite em pó desnatado & 26,00 & 18,00 & 2,50 \\
\hline Açúcar & 2,00 & 2,00 & 2,00 \\
\hline Sal & 0,50 & 0,50 & 0,50 \\
\hline Calcário calcítico & 0,66 & 0,65 & 0,70 \\
\hline Fosfato bicálcico & 1,44 & 1,04 & 1,25 \\
\hline Anti-oxidante & 0,01 & 0,01 & 0,01 \\
\hline L-Lisina & 0,14 & 0,14 & 0,22 \\
\hline DL-Metionina & 0,15 & 0,06 & 0,07 \\
\hline L-Treonina & 0,11 & 0,07 & 0,08 \\
\hline Suplemento mineral ${ }^{1}$ & 0,20 & 0,20 & 0,20 \\
\hline Suplemento vitamínico ${ }^{2}$ & 0,30 & 0,30 & 0,30 \\
\hline Óleo vegetal & 5,00 & 5,00 & 3,50 \\
\hline Veículo ${ }^{3}$ & 2,50 & 2,50 & 1,50 \\
\hline Total & 100,00 & 100,00 & 100,00 \\
\hline \multicolumn{4}{|c|}{ Níveis Nutricionais - Composição Calculada } \\
\hline Energia metabolizável (kcal/kg) & 3.500 & 3.487 & 3.366 \\
\hline Proteína bruta (\%) & 21,10 & 20,50 & 20,00 \\
\hline Cálcio (\%) & 1,00 & 0,82 & 0,72 \\
\hline Fósforo disponível (\%) & 0,56 & 0,42 & 0,34 \\
\hline Lisina $(\%)$ & 1,50 & 1,40 & 1,30 \\
\hline Metionina (\%) & 0,56 & 0,45 & 0,38 \\
\hline Met+Cistina (\%) & 0,87 & 0,75 & 0,72 \\
\hline Treonina (\%) & 0,98 & 0,90 & 0,84 \\
\hline Triptofano $(\%)$ & 0,27 & 0,26 & 0,25 \\
\hline
\end{tabular}

1 - Suplemento mineral - níveis de garantia por kg de ração: Ferro $80 \mathrm{mg}$, Cobre $70 \mathrm{mg}$, Manganês $40 \mathrm{mg}$, Zinco $80 \mathrm{mg}$, Cobalto $0,72 \mathrm{mg}$, Iodo $1,68 \mathrm{mg}$, Selênio $0,24 \mathrm{mg}$.

2 - Suplemento vitamínico - níveis de garantia por kg de ração: Vit A 12.000 UI, Vit D-3 3.000 U.I, Vit E 30 mg, Vit K-3 9 mg, Vit $\mathrm{B}_{12} 27 \mathrm{mcg}$, Vit $\mathrm{B}_{2} 11,4 \mathrm{mg}$, Biotina 0,12mg, Pantotenato de Cálcio $18 \mathrm{mg}$, Niacina $42 \mathrm{mg}$, Colina $300 \mathrm{~g}$.

3 - Os aditivos testados (T2-1\% de glutamina; T3-0,2\% de prebiótico) foram incluídos em substituição ao veículo (caulim), com exceção do óleo de peixe que foi incluído em substituição ao óleo de soja. 
O Experimento 2 foi realizado para determinar a quantidade total do DNA, proteína da mucosa intestinal e a expressão da enzima ornitina descarboxilase. Para isso, foram utilizados 45 leitões desmamados aos 21 dias de idade, pesando em média $6,17 \pm 0,55 \mathrm{~kg}$ e submetidos aos mesmos tratamentos do Experimento 1, sendo utilizada somente a dieta préinicial. No dia do desmame (grupo controle) foi abatido um grupo de cinco leitões e aos sete e aos 14 dias pós-desmame foram abatidos cinco animais de cada tratamento. As amostras da porção média do intestino delgado foram colhidas e imediatamente congeladas em nitrogênio líquido e mantidas à temperatura de $-70{ }^{\circ} \mathrm{C}$ para posterior análise.

O DNA total foi isolado da porção média do intestino delgado dos leitões segundo o método proposto por Wolff e Gemmill ${ }^{15}$.

As amostras foram preparadas a partir de 0,1 $\mathrm{g}$ de tecido congelado (raspado da mucosa intestinal), o qual foi triturado em graal na presença de nitrogênio líquido e transferido para um tubo cônico na presença de solução de lise (sacarose e proteinase $\mathrm{K}$ ), onde permaneceu a $37{ }^{\circ} \mathrm{C} / 12 \mathrm{~h}$. O lisado foi transferido para outro tubo e o DNA foi extraído com uma solução contendo fenol, clorofórmio e álcool isoamílico, posteriormente precipitado com isopropanol, enrolado na ponteira de uma pipeta Pasteur e banhado repetidamente em um tubo contendo etanol 70\%. Após a lavagem do DNA, ele foi colocado em uma solução TE $(\mathrm{pH} 7,4)$ e ficou em repouso até soltar da ponteira.

Foi feita nova extração com uma solução de fenol, clorofórmio e álcool isoamílico e o DNA foi precipitado com acetato de amônio $(7,5 \mathrm{M}$ e pH 7,4) e etanol absoluto e novamente enrolado em uma pipeta Pasteur e lavado repetidamente em etanol $70 \%$, posteriormente dissolvido em TE ( $\mathrm{pH} \mathrm{7,4).} \mathrm{Foi}$ realizada a leitura da concentração em espectrofotômetro a $260 \mathrm{~nm}$.

A proteína total foi determinada pelo método de Bradford $^{16}$, usando-se a soroalbumina bovina (BSA) como padrão.

A proteína da enzima ornitina descarboxilase foi determinada pelo método Dot Blotting, por filtração a vácuo, através do sistema de microfiltração "Bio Dot ${ }^{\mathrm{TM}}$ apparatus" da Bio-Rad.

As amostras foram preparadas a partir de $1 \mathrm{~g}$ de raspado da mucosa intestinal diluído em $5 \mathrm{~mL}$ de tampão de lise (Tris.HCl, 20mM, pH 7,5, NaCl $0,9 \%$, e $\beta$-mercaptoetanol $2 \mathrm{mM}$ ) homogeneizado em Turrax com pulsos de 30 segundos e sonicado por cinco minutos em Sonicador Bransan (Sonifier 250). O lisado total foi centrifugado a $30.000 \mathrm{~g}$, por 30 minutos sob refrigeração. $O$ sobrenadante foi homogeneizado e reservado para análise da proteína e determinação da ODC.

Foi utilizada membrana tipo nitrocelulose, previamente umedecida em água para aplicar $10 \mu \mathrm{g}$ de proteína total, com volume completado para 200 $\mu \mathrm{L}$ com água deionizada para cada amostra e, na ausência da proteína pura (ODC) foi feita a linearização com um pool de amostras dos animais abatidos no dia do desmame. A membrana foi colocada no aparato de Dot sob vácuo para filtrar. Após a filtração, a membrana foi lavada várias vezes com água deionizada e posteriormente foi lavada por 1 hora sob agitação leve com $20,0 \mathrm{~mL}$ de TBS-Leite (10mMTris. $\mathrm{HCl}, \mathrm{pH} 8,0 ; 0,15 \mathrm{M} \mathrm{NaCl} ; 5,0 \%$ leite em pó desnatado) e Tween $20(0,02 \%)$.

A membrana foi então incubada com o anticorpo monoclonal específico para ODC (O-1136, Sigma) em uma diluição 1:500, na presença de 20 $\mathrm{mL}$ de TBS-Leite e Tween 20 por uma hora sob agitação e temperatura ambiente. Posteriormente, foram feitas quatro lavagens de cinco minutos cada, com TBS-T (TBS + 0,05\% Tween-20) e uma lavagem por 10 minutos com 20,0 mL de TBS. O anticorpo secundário (A-8924, Sigma), conjugado a uma anti-IgG de camundongo, foi utilizado para revelar o complexo antígeno-anticorpo, numa diluição de 15000, sendo incubada por 1 hora em TBS-Leite, procedendo com as lavagens descritas anteriormente.

A revelação foi feita com a utilização das seguintes soluções: $20 \mathrm{~mL}$ de tampão AP $(100 \mathrm{mM}$ Tris- $\mathrm{HCl} \mathrm{pH} 9,5 ; 100 \mathrm{mM} \mathrm{NaCl} ; 5 \mathrm{mM} \mathrm{MgCl} 2$ ). Em seguida foram colocados $132 \mu \mathrm{L}$ de NBT (nitro-blue tetrazolium chloride - $50 \mathrm{mg} / \mathrm{mL}$ de dimetilformamida 100\%), mais $66 \mu \mathrm{L}$ de BCIP (5 bromo-4-chloro-3-indolyl phosphate - $50 \mathrm{mg} / \mathrm{mL}$ de dimetilformamida $70 \%$ ), até visualização da banda correspondente à proteína (ODC). A reação foi interrompida com a lavagem da membrana com solução TCA a 3,0\%. Posteriormente, foi lavada com água deionizada e seca em temperatura ambiente. A leitura foi feita em densitômetro Shimadzu CS9301PC, a $595 \mathrm{~nm}$.

O delineamento experimental para ambos os experimentos foi em blocos casualizados, sendo que para o Experimento 1 foram utilizados quatro tratamentos (dietas) e seis repetições, e para o Experimento 2 foi utilizado um esquema fatorial $4 \times 3$ (quatro dietas $\mathrm{x}$ três épocas de abate), com cinco repetições, sendo a unidade experimental constituída por um animal nas duas ocasiões. As análises de variância foram realizadas através do procedimento GLM do SAS (SAS Institute Inc.), com as médias dos tratamentos comparadas pelo teste de Tukey (5\%). O comportamento da variável resposta em 
relação às idades de abate (dias pós-desmame) foi estimado pela análise de regressão linear, testando-se modelos polinomiais (primeiro e segundo graus).

\section{RESULTADOS E DISCUSSÃO}

As médias de ganho diário de peso, consumo diário de ração e conversão alimentar em função das dietas testadas, nas fases pré-inicial (desmame a 34 dias de idade), inicial 1 (35 a 47 dias de idade) e inicial 2 (48 a 61 dias de idade), bem como as probabilidades (teste F) obtidas pela análise de variância estão apresentadas na Tabela 2.

Os resultados mostraram que a adição de glutamina, prebiótico ou óleo de peixe às dietas de leitões desmamados não influenciaram $(\mathrm{P}>0,05)$ o desempenho animal em nenhuma das fases estudadas. Entretanto, Wu et al. ${ }^{9}$ observaram que a adição de $1 \%$ de glutamina na dieta mostrou uma melhora de $25 \%$ na eficiência alimentar dos leitões na segunda semana pós desmame.

Tabela 2 - Médias de ganho diário de peso, consumo diário de ração e conversão alimentar dos leitões de acordo com as fases pré-inicial (22 a 34 dias de idade), inicial 1 (35 a 47dias de idade) e inicial 2 (48 a 61 dias de idade)

\begin{tabular}{|c|c|c|c|c|c|c|c|c|c|}
\hline \multirow[t]{2}{*}{ Dietas } & \multicolumn{3}{|c|}{$\begin{array}{c}\text { Ganho Diário de } \\
\text { Peso (kg) }\end{array}$} & \multicolumn{3}{|c|}{$\begin{array}{c}\text { Consumo Diário } \\
\text { de Ração (kg) }\end{array}$} & \multicolumn{3}{|c|}{$\begin{array}{l}\text { Conversão } \\
\text { Alimentar }\end{array}$} \\
\hline & Pré & Inic. 1 & Inic. 2 & Pré & Inic. 1 & Inic. 2 & Pré & Inic. 1 & Inic. 2 \\
\hline Dieta Basal (DB) & 0,259 & 0,491 & 0,643 & 0,323 & 0,613 & 1,143 & 1,20 & 1,25 & 1,70 \\
\hline DB + Glutamina & 0,311 & 0,465 & 0,657 & 0,334 & 0,617 & 1,129 & 1,11 & 1,34 & 1,75 \\
\hline DB + Prebiótico & 0,269 & 0,471 & 0,666 & 0,315 & 0,597 & 1,150 & 1,19 & 1,29 & 1,64 \\
\hline DB + Óleo Peixe & 0,277 & 0,425 & 0,611 & 0,309 & 0,555 & 0,943 & 1,14 & 1,32 & 1,58 \\
\hline Média Geral & 0,278 & 0,463 & 0,644 & 0,321 & 0,596 & 1,104 & 1,16 & 1,30 & 1,67 \\
\hline CV\% & 19,53 & 16,63 & 8,87 & 12,85 & 12,10 & 10,29 & 7,90 & 7,55 & 9,93 \\
\hline Prob. (teste F) & 0,427 & 0,535 & 0,289 & 0,872 & 0,449 & 0,094 & 0,348 & 0,525 & 0,336 \\
\hline
\end{tabular}

Os resultados obtidos neste trabalho para os animais que receberam o tratamento com a adição da parede celular de levedura são diferentes daqueles encontrados por Spring ${ }^{17}$, que observou maior taxa de crescimento e melhor conversão alimentar de leitões na primeira semana pós-desmame. Esse autor também mostrou que o uso contínuo de parede celular de levedura até a fase de terminação, na dosagem de $0,2 \%$ da dieta, resultou em melhor conversão alimentar em comparação aos animais do grupo controle.

A substituição do óleo de soja da dieta pelo óleo de peixe não alterou o desempenho dos animais. Esses resultados estão de acordo com as observações de Thies et al. ${ }^{18}$, que verificaram mesmo ganho de peso para leitões que receberam óleo de soja, óleo de girassol, óleo de canola ou óleo de peixe.

Em relação à expressão da ornitina descarboxilase, a proteína e a relação proteína/DNA da mucosa intestinal, estas não foram alteradas $(\mathrm{P}>0,05)$ pela adição dos agentes tróficos (glutamina, prebiótico ou óleo de peixe), mas sim $(\mathrm{P}<0,05)$ pelo número de dias pós-desmame (Tabela 3).
A expressão da enzima ornitina descarboxilase sofreu uma queda brusca aos sete dias pós-desmame, quando comparada com o dia zero, e, posteriormente, teve seus valores aumentados aos 14 dias pós-desmame (Tabelas 3 e 4). A concentração de proteína, bem como a relação proteína/DNA apresentou a mesma tendência da ODC, denotando um estado de hipotrofia da mucosa, sugerindo que o processo de síntese proteica no intestino delgado ficou comprometido na primeira semana após o desmame e apresentou sinais de recuperação na segunda semana. Essa hipotrofia da mucosa e consequentemente das vilosidades pode levar a quadros de má digestão e absorção dos nutrientes o que pode acarretar uma diarreia pós-desmame ${ }^{19}$.

A adição de $1 \%$ de glutamina na dieta basal de leitões ao desmame aumentou a expressão da enzima ornitina descarboxilase em $41 \%$ em relação à dieta não suplementada, porém esses resultados não foram estatisticamente significativos.

Existem evidências de que a asparagina, glutamina, serina e glicina, quando presentes no conteúdo luminal, estimulam a expressão do gene da 
$\mathrm{ODC}^{15}$. A administração de glutamina resultou em aumento da atividade da ODC e da proliferação celular no jejuno de leitões ${ }^{6}$ e em aumento da expressão da ornitina descarboxilase em frangos de corte $^{10}$.

Tabela 3 - Valores médios da expressão da ornitina descarboxilase (ODC), da proteína, do DNA e da relação proteína/DNA da mucosa intestinal de leitões, em função do número de dias pós-desmame e das dietas

\begin{tabular}{|c|c|c|c|c|}
\hline Dias pós-desmame & ODC & Proteína* & DNA* & Proteína/DNA \\
\hline 0 & 12,49 & 135 & 14,63 & 9,21 \\
\hline 7 & 6,72 & 116 & 14,57 & 7,98 \\
\hline 14 & 7,80 & 116 & 14,44 & 8,10 \\
\hline \multicolumn{5}{|l|}{ Tratamento } \\
\hline Dieta basal (DB) & 7,77 & 120 & 14,50 & 8,32 \\
\hline DB + Glutamina & 10,97 & 124 & 14,40 & 8,65 \\
\hline DB + Prebiótico & 8,74 & 118 & 14,45 & 8,19 \\
\hline DB + Óleo Peixe & 8,45 & 128 & 14,80 & 8,67 \\
\hline \multicolumn{5}{|l|}{ Causas de Variação } \\
\hline Dias pós desmame & 0,002 & & 0,001 & \\
\hline Tratamento & 0,486 & 0,222 & 0,485 & 0,520 \\
\hline Idade $\mathrm{x}$ Tratamento & 0,225 & 0,750 & 0,737 & 0,943 \\
\hline CV $\%{ }^{* *}$ & 45,29 & 11,25 & 4,98 & 13,20 \\
\hline
\end{tabular}

* mg/g de mucosa

**CV\% - coeficiente de variação experimental.

Tabela 4 - Equações de regressão para a expressão da ornitina descarboxilase, proteína e relação proteína/DNA da mucosa intestinal dos leitões, em função do número de dias pós-desmame

\begin{tabular}{lcc}
\hline & \multicolumn{1}{c}{ Equação } & $\mathrm{R}^{2}$ \\
Variável (Y) & $\mathrm{X}=$ dias pós-desmame & 0,27 \\
Ornitina descarboxilase & $\mathrm{Y}=12,49-1,31 \mathrm{X}+0,07 \mathrm{X}^{2}$ & 0,29 \\
Proteína & $\mathrm{Y}=135-4,02 \mathrm{X}+0,19 \mathrm{X}^{2}$ & 0,21 \\
Relação proteína/DNA & $\mathrm{Y}=9,21-0,27 \mathrm{X}+0,01 \mathrm{X}^{2}$ & \\
\hline
\end{tabular}

\section{CONCLUSÕES}

A adição dos agentes tróficos não foi capaz de aumentar a taxa de renovação celular da mucosa intestinal de leitões ao desmame nem de melhorar o desempenho. Os leitões passam por um período de baixa proliferação celular na primeira semana pósdesmame e recuperam esta atividade na segunda semana.

\section{REFERÊNCIAS}

1. Rigueira LCM, Thomaz MC, Rigueira DCM, Pascoal LAF, Amorim AB, Budiño FEL. Effect of plasma and/or yeast extract on performance and intestinal morphology of piglets from 7 to 63 days of age. Revista Brasileira de Zootecnia. 2013; 42: 496-503.

2. Slezak K, Hanske L, Loh G, Blaut M. Increased bacterial putrescine has no impact on gut morphology and physiology in gnotobiotic adolescent mice. Beneficial Microbes. 2013; 4(3): 253-266.
3. Wang JY, Li J, Patel AR. Synergistic induction of ornithine decarboxylase by asparagine and gut peptides in intestinal crypt cells. American Journal of Physiology. 1998; 274(43): C1476-C1484.

4. Tabata K, Johnson LR. Mechanism of induction of mucosal ornithine decarboxylase by food. American Journal of Physiology. 1986; 251(3): G370-G377.

5. Wang JY, Viar MJ, Blanner PM, Johnson LR. Expression of the ornithine decarboxylase gene in response to asparagines in intestinal epithelial cells. American Journal of Physiology. 1996; 271: G164-G171.

6. Kandil HM, Argenzio RA, Chen W, Berschneider HM, Stiles AD, Westwick JK, Rippe RA, Brenner DA, Rhoads JM. L-Glutamine and L-asparagine stimulate ODC activity and proliferation in a porcine jejunal enterocyte line. American Journal of Physiology. 1995; 269:G591G599.

7. Lin CH, Correia L, Tolia K, Gesell MK, Tolia V, Lee PC, Luk GD. Early weaning induces jejunal ornithine decarboxylase and cell proliferation in neonatal rats. Journal of Nutrition. 1998; 128: 36-42. 
8. Passillé AMB, Pelletier G, Ménard J, Morriset J. Relationships of weight gain and behavior to digestive organ weight and enzyme activities in piglets. Journal of Animal Science.1989; 67: 2921-2929.

9. Wu G, Bazer FW, Wallace JM, Spencer TE. Intrauterine growth retardation: Implications for the animal sciences. Journal of Animal Science. 2006; 84: 2316-2337.

10. Maiorka A, Silva AVF, Santin E, Borges AS, Boleli IC, Macari M. Influência da suplementação de glutamina sobre o desempenho e o desenvolvimento de vilos e criptas do intestino delgado de frangos. Arquivo Brasileiro de Medicina Veterinária e Zootecnia. 2000; 52(5): 487490.

11. López-Pedrosa JM, Ramírez M, Torres MI, Gil A. Dietary phospholipids rich in long-chain polynsaturated fatty acids improve the repair of small intestine in previously malnourished piglets. Journal of Nutrition. 1999; 129(6):1149-1155.

12. Budiño FEL, Castro Júnior FG, Otsuk IP. Adição de frutoligossacarídeo na dieta de leitões desmamados: desempenho, incidência de diarréia e metabolismo. Revista Brasileira de Zootecnia. 2010; 39:2187-2193.

13. Moura JMLN, Gonçalves LAG, Grimaldi R, Soares MS, Ribeiro APB. Otimização das condições de produção de ésteres etílicos a partir de óleo de peixe com elevado teor de ácidos graxos $\omega$-3. Química Nova. 2006; 29(5): 956-959.

14. National Research Council. Nutrients Requirements of Swine. 10. ed. National Academy of Sciences. Washington. D.C., 1998. 189p.

15. Wolff R, Gemmill R. Purifying and analyzing genomic DNA. Genome analysis: a laboratory manual, 1997. 1, 82p.

16. Bradford MM. A rapid and sensitive method for quantitation of microgram quantities of protein utilizing the principle of protein-dye binding. Analytical Biochemistry. 1976; 72: 248-254.

17. Spring P. Yeast's secret weapon aids animal production. Feed Mix. 2000; 8(4): 32-34.

18. Thies F, Peterson LD, Powell JR, Nebe-Von-Caron G, Hurst TL, Matthews KR, Newsholme EA, Calder PC. Manipulation of the type of fat consumed by growing pigs affects plasma and mononuclear cell fatty acid compositions and lymphocyte and phagocyte functions. Journal of Animal Science. 1999; 77(1): 137-147.

19. Lima GJMM, Morés N, Sanches RL. As diarréias nutricionais na suinocultura. Acta Scientiae Veterinariae. 2009; 37(1): S17-S30.

Protocolado em: 10 dez. 2010. Aceito em: 30 out. 2014. 